\title{
BLICKDIAGNOSE
}
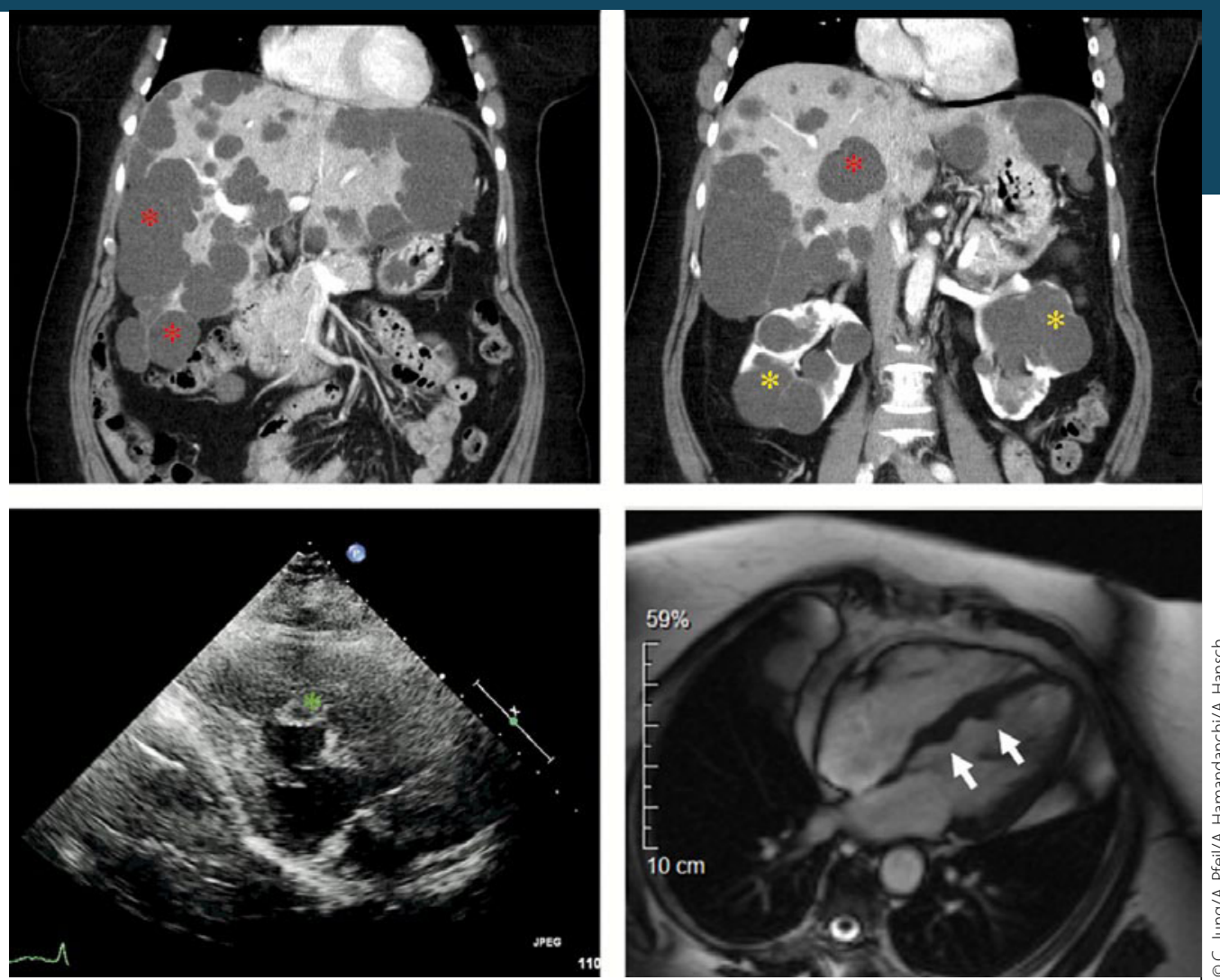

Zysten und Trabekel

\section{Was ist mit dieser Leber los?}

Eine 62-jährige Patientin kommt zur stationären Aufnahme bei progredienter Verschlechterung der Leberfunktion. Ein chronischer Alkoholabusus kann glaubhaft verneint werden. Im Rahmen der Familienanamnese gibt die Patientin an, dass beim Vater multiple Leberzysten festgestellt wurden. Beim Bruder wurden Nierenzysten festgestellt, ohne dass die Patientin dazu weitere Angaben machen kann. Weiterhin wurde bei der Patientin vor einigen Jahren ein Teratom des Ovars entfernt, welches einen Zahn enthielt.

— Im Rahmen der weiteren Abklärung fallen verschiedene Abnormitäten auf. Im Rahmen der abdominellen Computertomografie (obere Abbildungen) können multiple Leberzysten (exemplarisch mit roten Sternen gekennzeichnet) und multiple Nierenzysten (gelbe Sterne) entdeckt werden.

Die Echokardiografie (unten links, parasternale, lange Achse) zeigt zwei zusätzliche Muskelstränge, die den linken Ventrikel durchspannen (grüner Stern), welche im Kardio-MRT (unten rechts) im
Standbild noch als Septumverdickungen zur Abbildung kommen (Pfeile). In Zusammenschau der Befunde wird die Diagnose einer polyzystischen Leber- und Nierendegeneration gestellt.

Eine kausale Therapie für diese sehr seltene Erkrankung ist bislang nicht bekannt. Die Patientin wird an ein Transplantationszentrum zur Evaluierung einer Lebertransplantation überwiesen.

Keywords: polycystic degeneration of the liver and kidneys

- Dr. med. Christian Jung, Dr. med. Alexander Pfeil, Ali Hamadanchi, PD Dr. med. Andreas Hansch, Klinik für Innere Medizin I der Universitätsklinik Jena, Erlanger Allee 101, D-07747 Jena

\section{Info}

Weitere Blickdiagnosen finden Sie im Internet unter:

http://www.springermedizin.de/blickdiagnose 